designs for follow up in general practice geared to local and individual needs. ${ }^{3}$

There remains the question of the effectiveness of continuing education in changing the way that general practitioners assess and treat their patients with rheumatic complaints. Evaluation of schemes in both the United Kingdom ${ }^{14}{ }^{17}$ and the United States ${ }^{1819}$ showed that the knowledge, management skills, and referral patterns of such physicians can be improved and that this may lead to better outcomes for patients. ${ }^{19}$. The work of Stross in the United States has highlighted the role of "educationally influential physicians,". key people who are frequently consulted by their peers. Here perhaps is a further role for the consultant, either in person or as an agent, in developing key general practitioners who are influential among their fellow professionals.

Consultant rheumatologists represent a valuable resource of knowledge and experience in the treatment and management of rheumatic disorders and could thus help other people concerned with these disorders. A future challenge is to make better use of the consultants' specialist knowledge in the continuing education of general practitioners, at the same time providing the consultants with the opportunity to learn more about rheumatological problems as they are encountered in general practice.

This study showed that although a high proportion of consultant rheumatologists participated in continuing education of general practitioners, the types of teaching thought most desirable by consultants (that is, with close contact between consultant and general practitioner) and what should be taught (practical management) bore little resemblance to the predominant modes of teaching used. What was actually taught reflected the type of caseload more likely to be encountered in a hospital setting, with the emphasis on inflammatory arthropathies rather than the pattern of diagnoses made in general practice. The workshop organised by the Arthritis and Rheumatism Council initiated a discussion between specialists in rheumatology and representatives of the Royal College of General Practitioners; this is continuing and should bear fruit in terms of the continuing education and mutual understanding of both parties.
We thank Professor Philip Wood for his support and valuable comments on this project and the preparation of this paper, and Mrs Ann Papageorgiou for bibliographical help.

\section{References}

1 Donald AG. Continuing learning in practice project (CLIPP). foumal of the Royal College of General Practitioners 1984;34:242-5.

2 Scottish Council for Postgraduate Medical Education (SCPME). Maintaining standards in general practice. Edinburgh: SCPME, 1981.

3 Hart JT. Specialization in general practice. Journal of the Royal College of General Practitioners 1980;30:216-9.

4 Reedy BLEC, Gregson BA, Williams M. General practitioners and postgraduate education in the northem region. London: Royal College of General Practitioners, 1979. (Occasional paper 9.)

5 Wood J, Byrne PS. Section 63 activities. London: Royal College of General Practitioners, 1980. (Occasional paper 11.)

6 Pickup AJ, Mee LG, Hedley AJ. The general practitioner and continuing education. Foumal of the Royal College of General Practitioners 1983;33:486-90.

7 Hobbs R. It's come a long way. Br Med f 1984;288:885-7.

8 Wood PHN, Badley EM. Epidemiology of locomotor disorders in general practice. In: Jayson MIV, Million R, eds. Locomotor disability in general practice. Oxford: Oxford University Press, 1983:3-29.

9 Wood PHN, Benn RT. Undergraduate training in rheumatology in the United Kingdom. British foumal of Medical Education 1972;6:325-32.

10 Wood PHN, Badley EM, eds. People with arthritis deseroe well-trained doctors: report of a workshop organized by the Arthritis and Rheumatism Council. London: Arthritis and Rheumatism Council, 1979

11 Wright $\mathrm{V}$. The consultant rheumatologist and postgraduate education. $\mathrm{Br} \mathrm{Med}$ J 1983;287: $1158-9$.

12 Wood J, Byrne PS. Lecturing to general practitioners. Joumal of the Royal College of General Practitioners 1979;29:241-5.

13 Whitfield MJ. What do consultants think of general practice? foumal of the Royal College of General Practitioners 1980;30:228-9.

14 Griffen GA, Kaneti Barry SM. Muscle and joint pain: design and evaluation of courses for general practitioners. Journal of the Royal College of General Practitioners 1981;31:661-8.

15 Golding DN. Postgraduate education in rheumatology: who should teach what and to whom? $\mathcal{J} R$ Soc Med 1982;75:985-6.

16 Griffen GA. Continuing education in rheumatology. $\mathcal{F} R$ Soc Med 1982;75:985-6.

17 Grahame $R$, Gibson T, Dale $E$, et al. An evaluated programme of rheumatology training for general practitioners. Br $\mathcal{Y}$ R heumatol 1986;25:7-12.

18 Stross JK, Bole GG. Evaluation of an educational program for primary care practitioners, on the Stross JK, Bole GG. Evaluation of an educational program for pri
management of osteo-arthritis. Arthritis Rheum 1985;28:108-11.

19 Stross JK, Schumacher HR, Weisman MH, Spalding DM. Continuing medical education: changing behaviour and improving outcomes. Arthritis Rheum 1985;28:1163-7.

20 Royal College of General Practitioners. Second national mobility study. London: Office of Population Censuses and Surveys, 1974.

(Accepted 7 October 1986)

\title{
Prescribing in Pregnancy
}

\section{Treatment of asthma}

\author{
K FAN CHUNG， PETER J BARNES
}

About $1 \%$ of pregnant women suffer from active asthma..$^{1-3}$ Current evidence suggests that uncontrolled asthma may lead to maternal hypoxaemia with potentially grave consequences for the fetus. Asthma in pregnancy should therefore be treated promptly and appropriately to reduce perinatal mortality and morbidity. As in non-obstetric practice, management of pregnant women with

\footnotetext{
Department of Clinical Pharmacology, Cardiothoracic Institute, Brompton Hospital, London SW3 6HP

K FAN CHUNG, MD, MRCP, clinical lecturer

PETER J BARNES, DM, FRCP, professor of clinical pharmacology

Correspondence to: Dr Chung.

This series is edited by Dr PC Rubin.
}

asthma aims at preventing recurrent attacks of wheezing, status asthmaticus, and respiratory failure. Drugs that are teratogenic or detrimental to the fetus should obviously be avoided.

\section{Asthma and pregnancy \\ PULMONARY FUNCTION DURING PREGNANCY}

The enlarging fetus and the increased concentration of circulating hormones, such as progesterone and cortisol, contribute to several changes in pulmonary function in pregnancy. ${ }^{47}$ Reductions in residual volume and functional residual capacity occur before appreciable enlargement of the uterus. Spirometric tests of airway function such as forced expiratory volume in one second remain unchanged. Throughout pregnancy there is a progressive rise in 
minute ventilation, mostly due to an increased tidal volume, and arterial blood gas measurements reflect a compensated respiratory alkalosis. The partial pressure of arterial oxygen remains normal or is slightly increased. These changes have no effect on the course of asthma or on the fetus.

\section{FETAL OXYGENATION}

Maternal hypoxaemia and respiratory alkalosis, which may result during an acute attack of asthma, are detrimental to the fetus, particularly during the first trimester. The fetus exists in relative hypoxaemia with an umbilical venous pressure of oxygen of $4.3 \mathrm{kPa}$ ( $32 \mathrm{~mm} \mathrm{Hg}){ }^{8}$ This is compensated for by the fact that fetal haemoglobin binds more avidly to oxygen and releases it more efficiently in tissues. Fetal partial pressure of oxygen is adequately maintained provided inspired maternal oxygen is at least $7 \%$, but the fetus has a reserve of oxygen lasting only two minutes. Hypocapnia, to values of $2.3 \mathrm{kPa}(17 \mathrm{~mm} \mathrm{Hg})$ or less, may substantially depress fetal oxygen values and may be associated with clinically depressed infants at birth. ${ }^{9}$ Hypocapnia causes constriction of the uterine arteries with subsequent reduction in placental blood flow and increases the affinity of maternal haemoglobin for oxygen. ${ }^{8}$

\section{EFFECT OF PREGNANCY ON ASTHMA}

A review of several retrospective and uncontrolled studies showed that in half of 1054 pregnancies patients reported no change in their asthma, $29 \%$ improved, and $21 \%$ became worse. ${ }^{10}$ The severity of asthma before pregnancy seems to determine the course during pregnancy. Thus patients with severe asthma before pregnancy tend to become worse during pregnancy and those with mild asthma usually show little change ${ }^{11}$; subsequent pregnancies show a similar pattern.

\section{EFFECT OF ASTHMA ON PREGNANCY AND THE FETUS}

One study showed that mothers with asthma had a higher incidence of maternal complications, such as pre-eclampsia, during pregnancy than a control group of pregnant women. ${ }^{12}$ There is also a higher incidence of perinatal mortality in infants of asthmatic mothers, and a slight increase in the incidence of premature births. ${ }^{212}$ In a study of 55 women with asthma severe enough to require treatment with oral corticosteroids during their pregnancies the incidence of maternal and fetal morbidity and mortality was not increased when compared with that of a control group. ${ }^{13}$ This study suggested that adequate control of asthma may prevent the effects of asthma on pregnancy and on the fetus.

\section{Drug treatment of asthma during pregnancy}

The main classes of antiasthmatic drugs are: $(a)$ bronchodilators, such as $\beta$ adrenergic agonists and theophyllines, and $(b)$ prophylactic or anti-inflammatory agents such as corticosteroids (oral or inhaled) and sodium cromoglycate. Their use in pregnant women with asthma has been reviewed elsewhere. ${ }^{10} 14$ is

\section{$\beta$ ADRENOCEPTOR AGONISTS}

$\beta_{2}$ Adrenoceptor agonists are extremely effective bronchodilator agents in asthma. They should be given as an aerosol and are the drugs of choice for treating episodic wheezing and acute asthmatic attacks during pregnancy. There are minimal maternal side effects such as tachycardia, nervousness, and muscle tremor.

Teratogenesis has not been reported with the $\beta_{2}$ adrenergic agonists such as salbutamol and terbutaline. ${ }^{1416}$ Both drugs probably cross the placenta but this has not been confirmed. Terbutaline is secreted in breast milk, but it was not detected in the breast fed baby of a mother given an oral dose of terbutaline. ${ }^{17}$

Adrenaline and isoprenaline are best avoided during pregnancy. Adrenaline crosses the placenta and, in large doses, may cause fetal tachycardia and vasoconstriction of the uteroplacental circulation. A slightly increased incidence of congenital malformations has been reported after use of adrenaline during pregnancy. ${ }^{18}$ For similar reasons, ephedrine, which is only a mild bronchodilator, should not be used. Isoprenaline also crosses the human placenta and induces cardiac and aortic arch anomalies in chick embryo. These $\beta$ adrenergic drugs can be easily replaced by the more selective $\beta_{2}$ adrenergic agonists.

\section{THEOPHYLLINES}

Theophylline preparations are less effective as bronchodilators than $\beta_{2}$ agonists but may have additive effects after they have been given in maximally effective doses. Theophylline may be added to maintenance treatment if adequate control of asthma is not achieved with an inhaled $\beta_{2}$ agonist and inhaled corticosteroid. Another common indication for theophylline is the control of nocturnal asthma and early morning wheeze.

Although theophylline has been reported to induce chromosome breaks in human lymphocytes in culture, congenital anomalies did not occur in 117 women taking the drug during the first trimester..$^{18}$ Theophylline crosses the placenta and attains similar concentrations in maternal and fetal circulations. ${ }^{19}$ It also appears in the milk of mothers taking the drug with a milk to plasma ratio of about 0.7 ; the maximum concentration in milk occurs two hours after the peak serum concentration..$^{20} \mathrm{~A}$ breast fed baby has been estimated to receive less than $10 \%$ of the mother's dose. Tachycardia and transient jitteriness have been reported in three newborn infants whose mothers had blood concentrations of theophylline within the therapeutic range. Excessive irritability in breast fed infants of mothers receiving theophylline may be a sign of theophylline toxicity in the infant. Breast feeding before taking the scheduled dose of theophylline reduces neonatal exposure to the drug. No long term adverse effects have been reported in infants of mothers receiving theophylline throughout pregnancy.

There is limited information on the effects of pregnancy on theophylline pharmacokinetics. Blood concentrations of theophylline should be monitored to avoid underdosing or overdosing.

\section{CORTICOSTEROIDS}

Corticosteroids are powerful, effective agents for the treatment of acute, severe attacks of asthma and of chronic asthma. Steroid aerosols give treatment equivalent to a substantial dose of oral steroids but avoid systemic side effects.

The safety of inhaled beclomethasone dipropionate has been evaluated in $\mathbf{4 5}$ pregnancies in $\mathbf{4 0}$ women with severe asthma taking a mean daily dose of $336 \mathrm{mg} .{ }^{21}$ Beclomethasone aerosol was used regularly in 38 pregnancies from the time of conception. The risk of congenital malformations, spontaneous abortions, stillbirths, and neonatal deaths was within the normal range. In another study of 20 patients who became pregnant while taking an unstated dose of beclomethasone no congenital malformations or abortions were recorded.22

An increased incidence of cleft palate in the offspring of rabbits given cortisone acetate during pregnancy has been reported, but no increase in abnormalities was found in 145 infanis exposed to corticosteroids during the first trimester of pregnancy. ${ }^{18}$ Early reports linked prednisolone to an increased incidence of stillbirths and unexpected fetal distress due to placental insufficiency. ${ }^{23}$ These findings have not been confirmed in more recent studies, however, which found no increased risk of spontaneous abortion, congenital malformations, stillbirths, neonatal deaths, pre-eclampsia, or bleeding in 70 pregnancies in 55 patients with asthma receiving a mean daily dose of prednisolone $8 \cdot 2 \mathrm{mg} .{ }^{124}$ There was a slight 
increase in the incidence of premature birth, but this effect could have resulted from other factors.

Cortisol and corticosteroids cross the placenta rapidly, and most of the cortisol is converted rapidly into inactive cortisone by fetal enzymes. ${ }^{25}$ Dexamethasone crosses the placenta in high concentrations, achieving similar values in the fetus. ${ }^{26}$ On the other hand, prednisolone is transferred slowly and the concentration of active compound in fetal blood is $10 \%$ of that in the mother. ${ }^{27}$ Prednisolone equilibrates rapidly in the infant but is converted to the active prednisolone only slowly and is therefore functionally inactive in the fetus. It appears reasonable to prescribe either prednisone or prednisolone if steroids are to be used to treat asthmatic patients during pregnancy. Prednisone and prednisolone are secreted in breast milk in small amounts, ${ }^{28} 29$ but a dose of less than $30 \mathrm{mg} /$ day is unlikely to cause any problems in breast fed infants.

The incidence of hypoadrenalism in children of mothers taking corticosteroids is low, probably because of the widespread use of prednisolone or prednisone. Neonates whose mothers have taken prednisone throughout pregnancy have normal cortisol production.

\section{SODIUM CROMOGLYCATE}

Sodium cromoglycate is a useful prophylactic agent in some young patients with atopic asthma. Large intravenous doses of sodium cromoglycate in rats and rabbits do not have any teratogenic effects, and results of one large study suggest that it is safe in pregnant women with asthma using the recommended inhaled dosage throughout pregnancy. ${ }^{30}$ There are no data on the transfer of sodium cromoglycate across the placenta. Because it is poorly absorbed after inhalation ${ }^{31}$ the amounts available for transfer across the placenta are insignificant.

\section{Management of asthma in pregnant and nursing mothers}

In common with several other medical complications of pregnancy the management of asthma should ideally begin before conception. Treatment should be optimised: if possible the number of drugs taken should be reduced and undesirable agents (such as antihistamines) discontinued. As with non-pregnant patients, the aim of treatment is to control and prevent acute episodes of asthma.

Measures such as avoiding allergens or known triggering factors and treatment of associated reflux oesophagitis and rhinitis or sinusitis may lead to an improvement in control. Treatment with $\beta_{2}$ agonist drugs in aerosol form is preferable to oral treatment, with a reduction in systemic side effects. Theophyllines should be added only when both inhaled $\beta_{2}$ agonists and corticosteroids fail to control asthma. Sodium cromoglycate may be useful in allergic asthmatics who have previously responded to it.

The treatment of acute severe episodes of asthma in pregnant patients is similar to that in non-pregnant patients. $\beta_{2}$ Agonists given by inhalation from a nebuliser and oral corticosteroids, preferably prednisolone or intravenous methylprednisolone, remain the drugs of choice. Arterial blood gases should be checked to avoid levels of hypocapnia and hypoxaemia which are detrimental to the fetus, and supplementary oxygen should be given. Intravenous theophylline may be added to the treatment of acute asthma when there is little or slow response to the combination of $\beta_{2}$ agonists and corticosteroid; serum theophylline concentrations should be monitored closely.

Maintenance treatment with oral or inhaled corticosteroids is indicated if repeated short courses of oral steroids are continually followed by relapse and if $\beta_{2}$ agonists fail to control symptoms. It is desirable to use single daily doses of prednisone and to change to inhaled corticosteroids such as beclomethasone dipropionate as soon as symptoms are controlled. Inhaled corticosteroids can usually be substituted in patients requiring low doses of maintenance oral corticosteroids. At the time of delivery patients previously treated with oral corticosteroids should be given hydrocortisone $100 \mathrm{mg}$ every eight hours, starting at presentation and continuing for 24 hours after delivery.
There is no reason why an asthmatic mother who takes antiasthmatic drugs should not breast feed her infant. In general a regimen of inhaled $\beta_{2}$ agonist, theophylline in the therapeutic range, and oral or inhaled corticosteroids should be safe and effective for the mother and her baby.

\section{References}

1 Schaefer G, Silverman F. Pregnancy complicated by asthma. Am f Obstet Gynecol 1961;82:182-91

2 Gordon M, Niswander KR, Berendes H, Kantor AG. Fetal morbidity following potentially anoxigenic obstetric conditions: VII. Bronchial asthma. Am f Obstet Gynecol 1970;106:421-9. $3 \mathrm{de}$ Swiet M. Diseases of the respiratory system. Clin Obstet Gynaecol 1977;4:287-96.

4 Gazioglu K, Kaltreider NL, Rosen M, Yu PN. Pulmonary function during pregnancy in normal women and in patients with cardiopulmonary disease. Thorax 1970;25:445-50.

5 Knuttgen HG, Emerson K. Physiological response to pregnancy at rest and at exercise. $\mathcal{F} \mathrm{Appl}$ Physiol 1974;36:549-53.

$6 \mathrm{Lim}$ VS, Katz AI, Lindheimer MD. Acid-base regulation in pregnancy. Am $\mathcal{J}$ Physiol 1976;231:1764-70.

7 Milne JA. The respiratory response to pregnancy. Postgrad Med f 1979;55:318-24.

8 Wulf KH, Kunzel W, Lehmann V. Clinical aspects of placental gas exchange. In: Lango LD, Bartels $\mathrm{H}$, eds. Respiratory gas exchange and blood flow in the placenta. Bethesda, Maryland: National Institute of Health, Public Health Service, US Department of Health, Education, and Welfare, 1972:505-21.

9 Moya F, Marishima HO, Shnider SM, James LS. Influence of maternal hyperventilation on the newborn infant. Am 7 Obstet Gynecol 1965;91:76-84.

10 Turner ES, Greenberger PA, Patterson R. Management of the pregnant asthmatic patient. Ann Intern Med 1980;6:905-18.

11 Gluck JC, Gluck PA. The effects of pregnancy on asthma: a prospective study. Ann Allergy 1976;37:164-8.

12 Bahna SL, Bjerkedal T. The cause and outcome of pregnancy in women with bronchial asthma. Allengy 1972;27:397-406.

13 Schatz M, Patterson R, Zeitz S, O'Rourke J, Melan H. Corticosteroid therapy for the pregnant asthmatic patient. FAMA 1975;233:804-7.

14 Romero R, Berkowitz R. The use of anti-asthmatic drugs in pregnancy. In: Niebyl JR, ed. Drug use in pregnancy. Philadelphia: Lea and Fabiger, 1982:41-59.

15 Greenberger PA, Patterson R. Management of asthma during pregnancy. $N$ Engl I Med 1985;312:897-902.

16 Mintz S. Pregnancy and asthma. In: Weiss EB, Segal MS, Stein M, eds. Bronchial asthma, mechanisms and therapeutics. 2nd ed. Boston: Little Brown Co, 1985:878-91.

17 Lonnerholm G, Lindstrom B. Terbutaline excretion into breast milk. Br 7 Clin Pharmacol 1983;13:729-30.

18 Heinonen OP, Slone D, Shapiro S. Birth defects and drugs in pregnancy. Littleton: Publishing Sciences Group, 1977.

19 Labovitz E, Spector S. Placental theophylline transfer in pregnant asthmatics. FAMA 1982;247 786-8.

20 Yurchek AM, Jusko WJ. Theophylline secretion into breast milk. Pediatrics 1976;57:518.

21 Greenberger PA, Patterson R. Beclomethasone dipropionate for severe asthma during pregnancy. Ann Intern Med 1983;98:478-80.

22 Morrow-Brown H, Storey G. Beclomethasone dipropionate aerosol in long-term treatment of perennial and seasonal asthma in children and adults: a repart of five and half years experience in 600 asthmatic patients. Br $\mathcal{A}$ Clin Pharmacol 1977;4:529S-67S.

23 Warrell DW, Taylor $R$. Outcome for the fetus of mothers receiving prednisolone during pregnancy. Lancet 1968;i:117-8.

24 Snyder RD, Snyder D. Corticosteroid for asthma during pregnancy. Ann Allergy 1978;41:340.

25 Murphy BE, Clark SJ, Donald IR, Pinsky M, Vedady D. Conversion of maternal cortisol to cortisone during placental transfer to the human foetus. Am 7 Obstet Gymecol 1974;118:538-41.

cortisone during placental transfer to the human foetus. Am $f$ Obstet Gynecol 1974;118:538-41. Osathanonsh A, Tulchinksy D, Kamali H, Fencl MD, Taeusch HW. Dexam

27 Beitins IZ, Bayard F, Ances IG; Kowaski A, Migem CJ. The transplacental passage of prednisone eitins IZ, Bayard F, Ances IG; Kowaski A, Migem CJ. The transplacen

28 McKenzie SA, Sellers JA, Agnew JE. Secretion of prednisolone into breast milk. Arch Dis Child 1975;50:894-6.

$29 \mathrm{Katz}$ FH, Duncan BR. Entry of prednisone into human breast milk. $N$ Engl $\mathcal{J}$ Med 1975;293:1154.

30 Wilson J. Utilisation du cromoglycate de sodium au cours de la grossesse. Acta Therapeutica 1982;8(suppl):45-51.

31 Walker SR, Richards AJ, Paterson JW. The absorption, excretion and metabolism of disodium $\left({ }^{14} \mathrm{C}\right)$ cromoglycate in man. Biochem $\mathcal{f}$ 1971;125:27.

Is a chest $x$ ray or a Heaf test more appropriate as a screening test for tuberculosis for long term overseas vistitors coming, say, from the Indian subcontinent to the United Kingdom?

A chest $x$ ray examination would be more appropriate as a screening test in the circumstances described. It would give information of immediate relevance by showing whether a person had evidence of pulmonary tuberculosis, thus identifying those who might be infectious and need treatment. Clearly it would not show whether there might be a tuberculous process elsewhere. A Heaf test in arrivals from the Indian subcontinent and many other parts of the world would often be positive but would not show whether the person had active tuberculosis. The younger the individual who has a positive tuberculin test the more likely that the infection will have been recent and may be active. It is desirable that so far as possible a screening test should be immediate, and since tuberculin tests require to be performed and read such tests may in practice prove more difficult to administer. The most useful single screening test is thus undoubtedly a chest radiograph at the point of arrival. - G W POOLE, consultant respiratory physician, London. 